\title{
Hazard Communication in a Large U.S. Manufacturing Firm: The Ecology of Health Education in the Workplace
}

\author{
Thomas G. Robins, MD, MPH \\ Susan Klitzman, DrPH
}

This article describes the design, implementation, and evaluation of a workplace health and safety education program intended to bring a large U.S. manufacturing firm into compliance with a Federal regulation, the Hazard Communication Standard. The methods of program delivery and levels of resources allocated were decided by local plant management and union representatives resulting in marked variations among the five plants studied. These differences in program delivery were associated with differences in employee assessment of the training's usefulness, changes in employee work practices, working conditions, and organizational handling of health and safety problems. In all five plants, the program evidenced indirect beneficial effects on the use of hazard control measures and organizational approaches to health and safety issues which went beyond the requirements of the federal Standard. The results appear wellexplained by an ecological model which views health and disease as outcomes of a complex system of interactions between the individual worker and multiple levels of environmental influences. Implications of these findings for health educators are discussed.

\section{INTRODUCTION}

An estimated 390,000 new cases of work-related illness occur in the U.S. each year.' Among the reported cases of occupational illness, the majority are due to chemical exposures. ${ }^{2}$ Because occupational diseases arise out of manmade conditions, they are potentially preventable by altering those same conditions. In the last century, there has been growing recognition of the health hazards associated with workplace exposures and of the importance of developing programs to improve worker health.

The authors would like to thank Barbara Israel and Bonnie Kay for their helpful comments on an earlier draft of this article.

Thomas G. Robins is with the Occupational Health Program, Department of Environmental and Industrial Health, School of Public Health, University of Michigan.

Susan Klitzman, is with the New York City Department of Health.

Address reprint requests to Thomas G. Robins, MD, MPH, Dept. of Environmental and Industrial Health, School of Public Health, University of Michigan, 1420 Washington Heights, Ann Arbor, MI 48 109-2029. 


\section{Occupational Health and Safety and Health Promotion}

Until recently most management conducted and sanctioned health and safety training programs have focused on altering worker behaviors likely to result in easily recognizable acute physical injury and immediate costs to employers in lost productivity and compensation claims. ${ }^{3}$ Most of these training programs have dealt exclusively with safety hazards and emphasized individual responsibility and individually oriented prevention strategies. ${ }^{4}$ Historically, little value has been placed on educating workers regarding chemical hazards which may not cause adverse health effects until many years after exposure. The influence of this orientation is evident in the 1948 edition of Patty's Industrial Hygiene and Toxicology which gives the following advice to industrial hygienists surveying plant exposures: "Any remark about measuring toxic vapors, seeing whether the air will make workers ill, or seeing whether it is safe to work here would be an ill-considered. . It is not that the workman should be deceived but rather that he should not be alarmed about something that he probably would not fully understand." 5 In contrast, organized labor's approach to worker health and safety has predominantly focused on changing the hazardous conditions faced by workers and on the worker's right to information about workplace health hazards.

Today, much of the emphasis in worksite health prevention and health education programs has shifted from work-related health risks to more general environmental or lifestyle related risks (e.g., smoking, nutrition and exercise). ${ }^{6}$ Programs for the prevention of adverse outcomes associated with these types of risks are enjoying a period of intense growth under the rubric of health promotion. The majority of these programs have targeted interventions at the level of the individual.

Despite their apparent differences in focus and orientation, the occupational health and safety and workplace health promotion movements share several common aspects. First, both are concerned with worker health. Second, both occur in workplace organizational contexts. Third, both are concerned with reducing the cost of disease and hence with preventing unnecessary illness. Finally, both frequently employ strategies based on education and behavioral change.

Recently, the promulgation of various "Right-to-Know" and hazard communication laws at the federal, state, and local level have opened up new opportunities for conducting health education in the workplace. These laws typically require that employers inform their workers about potential chemical hazards to which they are exposed, how to obtain information about these hazards and how to protect themselves from exposure.

This article will examine the implementation of a worker education program designed to meet the requirements of the Federal Hazard Communication Standard. The specific purposes of this article are: (1) to explain the training program design and to assess the extent to which the program was actually implemented according to the initial plan; (2) to examine the impact of the program both in terms of its mandated objectives as well as any indirect effects; and (3) to examine the implications of these findings for developing a model of effective workplace health and safety training and health promotion activities generally.

\section{Policy and Organizational Context}

In November, 1983 the Federal Occupational Safety and Health Administration (OSHA) promulgated the Hazard Communication Standard. The Standard initially 
applied only to employers in the manufacturing sector but has recently been expanded to cover all workers under OSHA's jurisdiction. ${ }^{8}$ The standard explicitly states that its implementation "will reduce the incidence of chemically-related occupational illnesses and injuries in employees. . Increased availability of hazard information will assist employers in these industries to devise appropriate protective measures, and will give employees the information they need to protect themselves."9 The standard contains specific provisions regarding the evaluation of health hazards, labelling of containers, use of chemical information sheets called Material Safety Data Sheets (MSDS), and training of employees. The standard requires that employees receive training about what hazardous substances they are or may be exposed to, the health and physical hazards associated with these substances, methods of detection of exposure or overexposure, and methods of protection from adverse effects. The initial standard required completion of training in the manufacturing sector by May 25, 1986. Additional key aspects of the standard are that is a performance oriented standard, it specifies what employers must do but not how they must do it; and, in contrast to most other OSHA standards, it is a generic standard covering a broad range of chemical hazards.

The education program described in this paper was designed to bring one large, multi-site industrial firm into compliance with the training requirements of the federal standard. The company involved employs approximately 110,000 hourly and 30,000 salaried workers at over 80 facilities in the U.S. The company maintains corporate medical, toxicology, industrial hygiene, and safety departments. Health and safety at the local plant level is handled by a plant safety engineer. The industrial union which represents most U.S. hourly employees of the company maintains a union-wide health and safety department. In addition, a paid, full-time union health and safety representative is present in each plant with 600 or more union members.

A recent union contract with the company established a National Joint Committee (NJC) and a jointly administered fund for health and safety training activities. The NJC agreed on the following elements for a program to bring the company into compliance with the federal HCS: (1) development of materials and training approach by a mutually selected third party: (2) use of a "train-the-trainer" structure, i.e. the third party would train company and union representatives from each local facility who would subsequently provide training to all employees at their facilities; and (3) training sessions would be conducted jointly by company-union teams.

The contract for developing a hazard communication training program (HCTP) was awarded to the Labor Studies Center of Michigan State University and the Department of Environmental and Industrial Health at the University of Michigan. University instructors were all educators in either occupational heal th or labor education.

The HCTP was carried out using a "train-the-trainer" design. A set of written materials organized into 21 modular units were developed and pilot-tested in a 5-day trainthe-trainer program. Units presented both general information on health and safety and hazard information on specific classes of chemicals. After a critique of the pilot session by company and union representatives, final program materials and the trainthe-trainer week format were developed. During the summer of 1985 , a total of 340 hourly and salaried trainers attended the five day training course.

University personnel had recommended to the company and the union that individuals having good communication skills, time availability, knowledge of health and safety, and the respect of the workface be selected as trainers. In practice most of the trainers who attended the training course were selected primarily on the basis of their 
job responsibilities. The majority of trainers were company safety engineers and union health and safety representatives with prior and continuing health and safety responsibilities at the local plant level.

The 5-day course for trainers included both a technical and an adult education component. Approximately two days were devoted to instruction on technical issues (general health and safety information and information on specific classes of hazardous chemicals or specific processes). The remaining three days were allocated to adult education principles, practice teaching, planning of in-plant training, and effective methods of securing the cooperation of in-plant management and of addressing employee concerns. Recommended guidelines were presented to trainers on how to organize the training sessions, which included delivery to groups of less than 30 employees, one hour or less of training received per day by an individual employee, and use of frequent discussion and question and answer periods. A more detailed description of the train-the-trainer course can be found elscwhere. ${ }^{10}$

Video programs to accompany each of the 21 written units were developed following the train-the-trainer sessions and became available to trainers about January 1986. Video programs and written materials cmphasized safe individual work practices, recognition of hazardous conditions and steps to be taken by hourly employees to have unsafe conditions corrected. After attending the course, trainers were responsible for planning a program at each of their local facilities and training all employees by May 1986. Most of the in-plant training of employees was conducted from January through May of 1986.

\section{DESIGN OF PROGRAM EVALUATION}

The evaluation was designed to examine: (1) how the program had been planned and implemented at each of five local facilities; and (2) what impact the program had on employee attitudes and knowledge, employee work practices, plant working conditions, and organizational mechanisms for addressing health and safety issues. The evaluation was conducted at five plants, representing a variety of manufacturing processes within the company. These plants will be referred to as A, B, C, D, and E. At each plant, all hourly and salaried trainers, a sample of hourly employees, front-line supervisors, and representatives from plant management, union leadership, and medical personnel were interviewed or surveyed. In addition, union and management representatives from the Joint National Committee were interviewed. Surveys and interviews include a mix of closed-ended and ópen-ended questions. Additional data collection methods have included observation of training sessions and review of records of use of protective equipment. A more detailed description of the evaluation methods has been given elsewhere. ${ }^{11,12}$ Three waves of data were collected: at the time training was conducted and at one year and again at two years after the completion of training. Results from the first two waves of data are presented here. Table 1 presents participation rates for these two waves. 


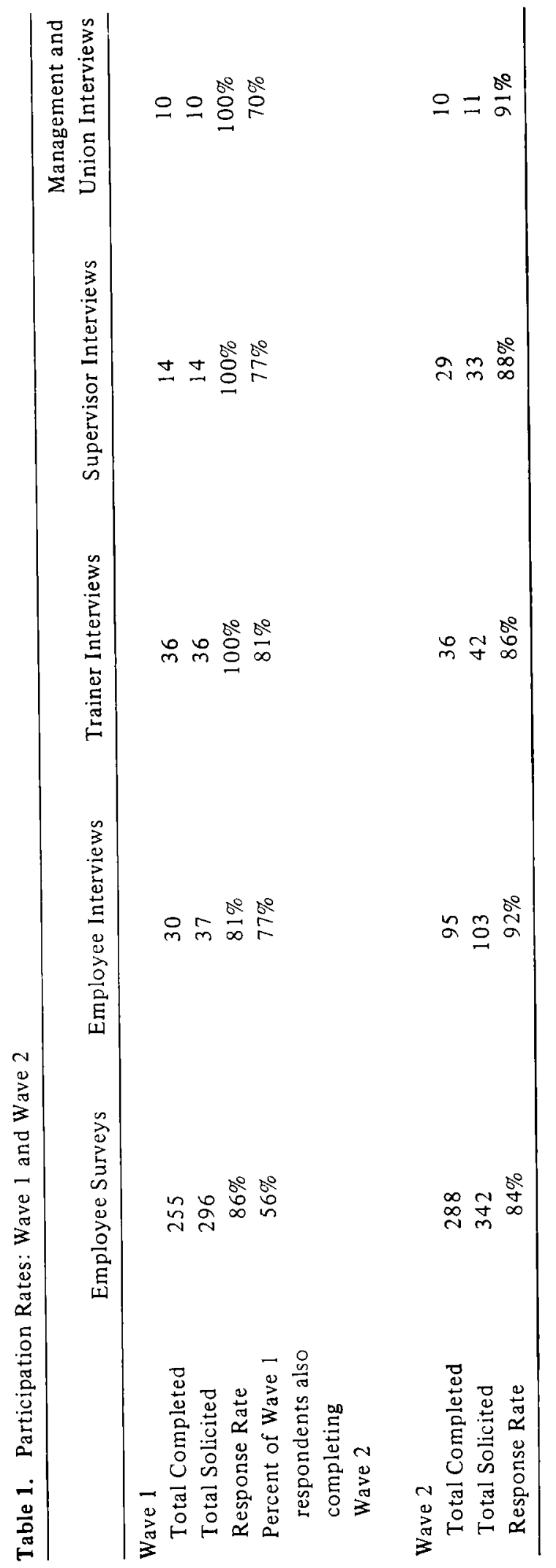




\section{RESULTS}

\section{Program Implementation}

Some aspects of the delivered training programs were very similar at all five sites: employees received training using the intended materials, training sessions wcre conducted jointly by hourly and salaried trainers, and over $95 \%$ of hourly employees and front-line supervisors completed the required training.

As shown in Table 2 there were also some striking differences in delivery of training among the five plants. In contrast to the other plants, at plants D and E sessions were frequently held at the end of the workshift. The training facility used and its rating by trainers and employees varied from conference rooms rated good to excellent at plants $\mathrm{B}$ and $\mathrm{C}$ to a cafeteria rated fair to poor at plant $\mathrm{E}$. The average group size receiving training varied from a low of 18 at plant $C$ to a high of 58 at plant $D$. Total trainer hours per week spent on the program per 100 employees varied from 19.0 at plant B to 2.8 at plant D. Finally, the format of a training session varied greatly among the plants. At plant $\mathrm{B}$, a training session consisted of a single 10 to 15 minute video followed by a verbal summary of the material using a flip chart and then a question and answer period. At plant $C$, a similar sequence of video, review and questions was repeated 6- or 7-times per session. At plants $\mathrm{A}$ and $\mathrm{E}$ three videos were shown, followed by a break or question and answer period, then three more videos were shown with a question and answer period at the end. At plant D, 13 videos were shown in a row followed by a question and answer period. The length of sessions also varied. At plant $B$, each session lasted for one half hour. At plants $A, C, D$, and $E$ each session lasted for two and a half to three hours.

In interviews with management and union representatives at each plant and members of the National Joint Committee (NJC), it was suggested that the variation in program implementation was explained by two major factors: first, allocation of funds for trainer time and employee release time was at the discretion of the different company divisions and/or the local plants; second, most decisions about length and format of training units, number of employees attending sessions, etc. were made at the local plant level. Corporate and union officials negotiated with individual plants only if local management and union could not reach agreement on how training should be done. The way in which training was planned and implemented appeared strongly influenced by the role the local union played in each plant. For example, at plant B management suggested a total of four hours of training per employee while the union proposed and won half-hour sessions for each unit to be covered. Management favored a group size of 70-80 employees, while the union insisted on smaller groups and the training of additional trainers. At plant $C$ the union was able to negotiate an agreement that skilled tradespeople should be provided with a half-hour of training per unit.

Less favorable training conditions existed at the other three plants. At these plants, the local union appeared to play a less active role in negotiations. Some respondents at these sites mentioned that management had either underestimated the magnitude of the task or advocated less costly training methods, e.g., simply sending people information packets and having someone answer their questions at a later time.

Members of the NJC as well as local plant management and union representatives identified one of the major problems with the program as the considerable variation in 


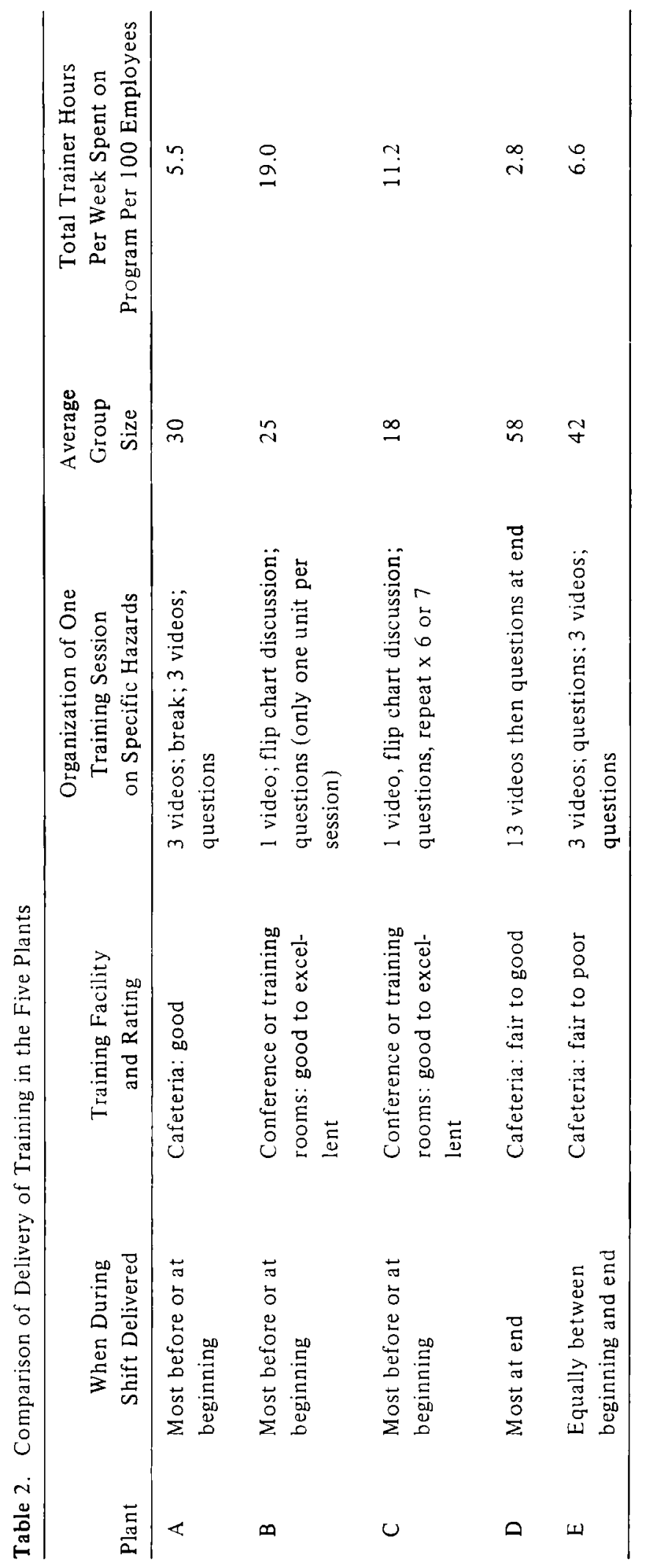




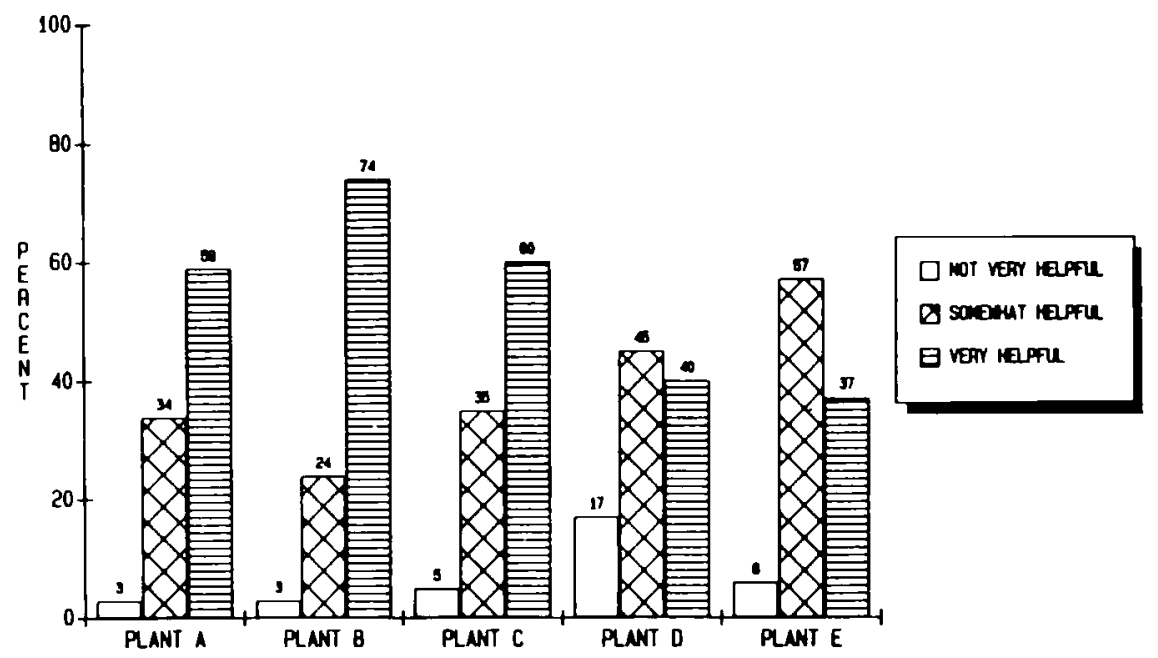

Figure 1. Program Usefulness in Recognizing Hazards Reported by Employees.

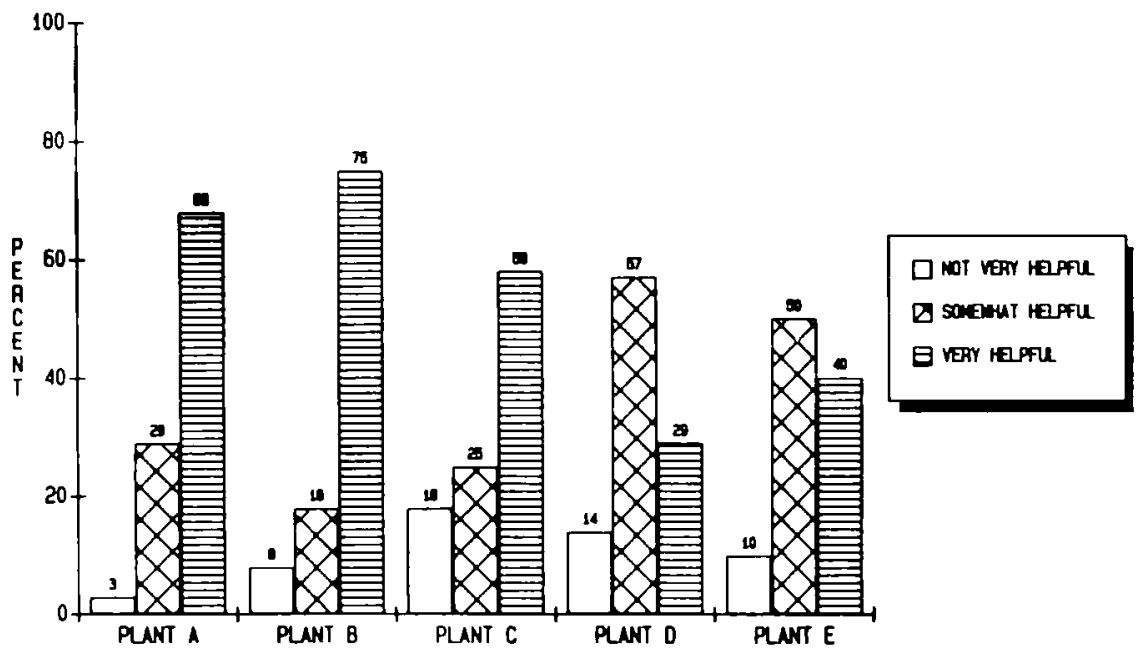

Figure 2. Program Usefulness in Knowing How to Get Information Reported by Employees.

training implementation because of the absence of more specific guidelines. NJC members also suggested that the planning of this program should have started earlier and included greater efforts to involve middle and upper level management.

\section{Program Usefulness}

Figures 1 through 3 present data on how useful employees found the training program in three areas when they were surveyed during the second wave of data collection one year after program completion. In each of the three areas: recognizing health hazards, knowing how to get information, and knowing how to handle hazardous situations, employees in plants $\mathrm{A}, \mathrm{B}$, and $\mathrm{C}$ rated the program as more useful than those in plants $D$ and $E$. The pattern of responses is similar to those observed during the first survey on these same questions. 


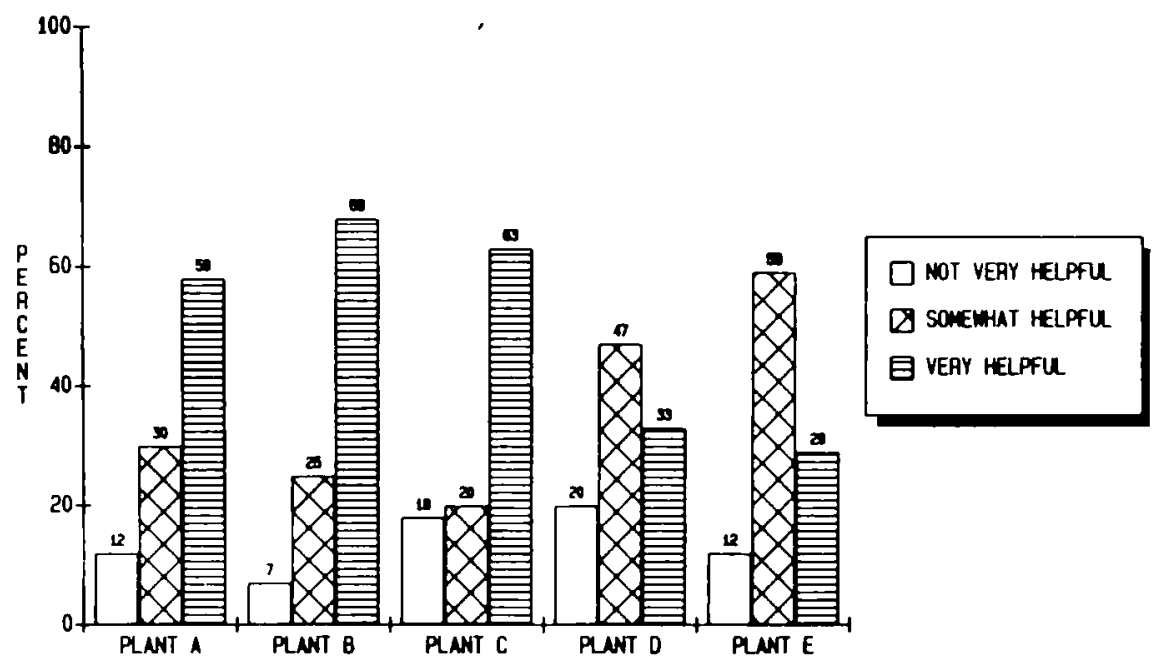

Figure 3. Program Usefulness in Knowing How to Handle Hazardous Situations Reported by Employees.

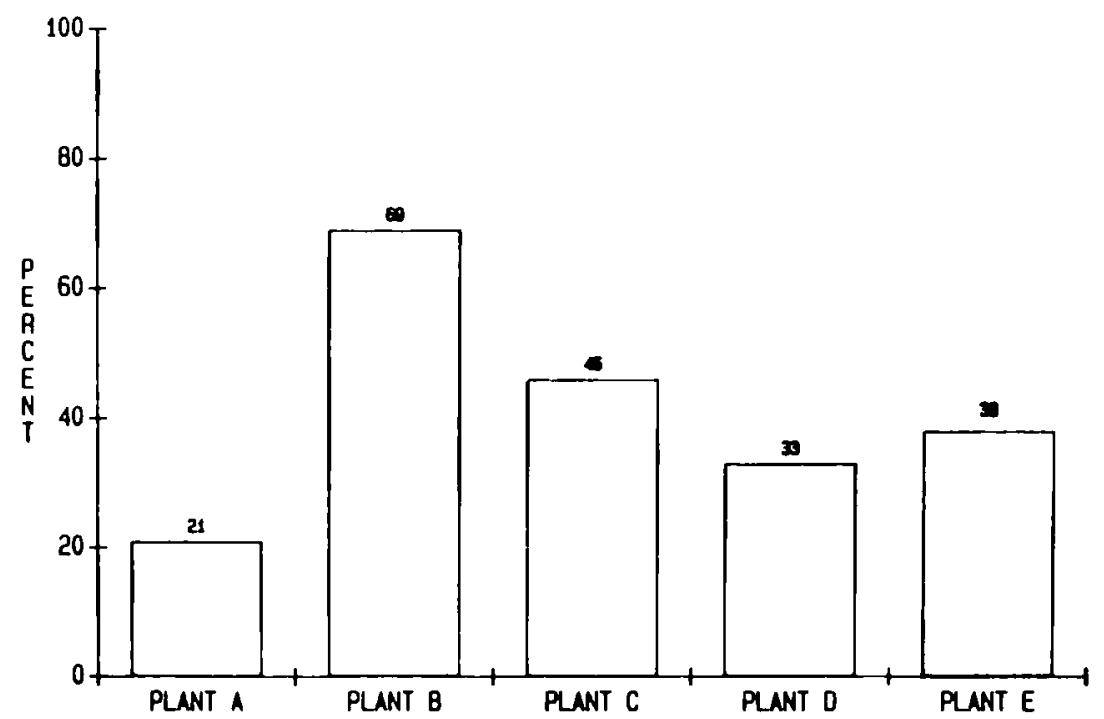

Figure 4. Mean Percent of Change in Work Practices Reported by Employees since Training Program.

\section{Work Practices}

\section{Hourly Employees}

In the 1-year follow up survey, $60 \%$ of hourly employees indicated that they had made changes in their work practices because of the program. At the 2-year follow-up $42 \%$ of employees still reported having changed their work practices because of the program with a range from $21 \%$ in plant $A$ to $69 \%$ in plant B (see Fig. 4).

When asked what changes they made in their work practices, employees most often said they read labels on containers, were more aware of potential dangers, avoided hazardous areas, and used protective equipment. Some typical responses were: 
(I) avoid contact with hazardous substances; (I'm) less likely to enter an area which (I) suspect may be hazardous.

Industrial electrician

(I) wear rubber gloves when working with cleaning solvents. (1) open (the) door for ventilation when working with gasoline.

Production worker

(I) check what a material is, use more protective equipment, and (am) generally more a ware.

Plumber/pipefitter

Hourly employees were also asked how often they followed a series of specific recommended work practices. Those who reported a change in their direct supervisor's attitudes toward health and safety were significantly more likcly to follow recommended practices.

\section{Supervisors}

Sixty-two percent of supervisors said they had changed their own work practices because of the program. Frequently reported changes included greater avoidance of hazards and ensuring that hourly employees were following recommended practices. Some typical responses were:

(I'm) more aware of some hazards and (I) talk to health and safety people about (them).

(I) don't open containers until I read the label. (I) wear gloves when I do work.

(I'm) quick to make sure employees wear the proper equipment and use safe work practices.

When asked if they had changed the way they respond to workers' requests for information on hazards or protective equipment, 64\% of the supervisors said "yes." Most said they respond more quickly, and several said they now have more information to give in response.

\section{Working Conditions}

Employees were asked whether specific hazard control measures had been taken on their job and, for those which had been taken, whether they were instituted before or after the training program began. Among the specific hazard control measures, the greatest percentage of employees reported increases in informational measures (labeling of containers (26\%), posting of signs (28\%), and availability of MSDSs (56\%)) and in substitution of safer chemicals for more hazardous ones (42\%). In addition, almost all employees said personal protective equipment (PPE), such as gloves and respirators, was available ( $96 \%$ one year after program completion). Smallest increases in control measures were reported for physical measures (such as use of exhaust ventilation $(10 \%)$ and new, safer machinery $(13 \%))$ and maintenance of equipment (8\%). Typical employee comments include: 


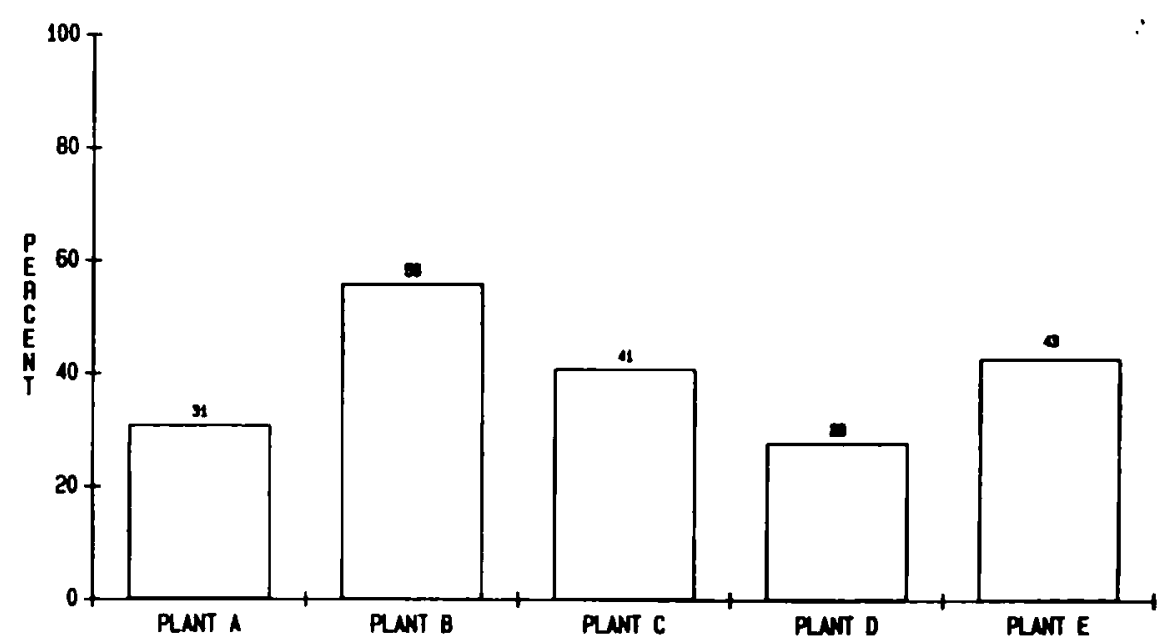

Figure 5. Percent of Applicable Control Measures Implemented since Training As Reported by Employees.

There are more signs, and all containers are labeled now.

They clean the oil off the floor every morning; they enforce better housekeeping, once a week we clean up the area.

Respirators are more available. There are Viton gloves now for the use of solvents.

There are changes in coolants and replacement of cutting oils with safe materials.

A composite measure of employee reported changes in working conditions was highest for plant $B$, intermediate for plants $C$ and $E$, and lowest for plants $A$ and $D$ (See Fig. 5).

Trainers also reported marked increases in substitution of safer chemicals and availability of PPE and much lower increases for physical measures and maintenance of equipment. Typical comments by trainers include:

Engineers are more aware of what they buy now; they pick the least dangerous materials.

We can usually get (the PPE) we want now; management is more willing to supply equipment; we get a greater response from company health and safety people.

Health and safety reps are better informed. Tests are done now before respirators are fitted.

Information on the availability and usage of personal protective equipment (PPE) collected through interviews and surveys was supplemented by examining computerized and written records of PPE usage maintained by the local plants. Only for two of the plants ( $B$ and $E$ ) was information available both for the year of training implementation (1986) and the preceding year for baseline comparisons. A general trend toward increased usage of PPE in 1986 as compared to 1985 was present in both plants. 


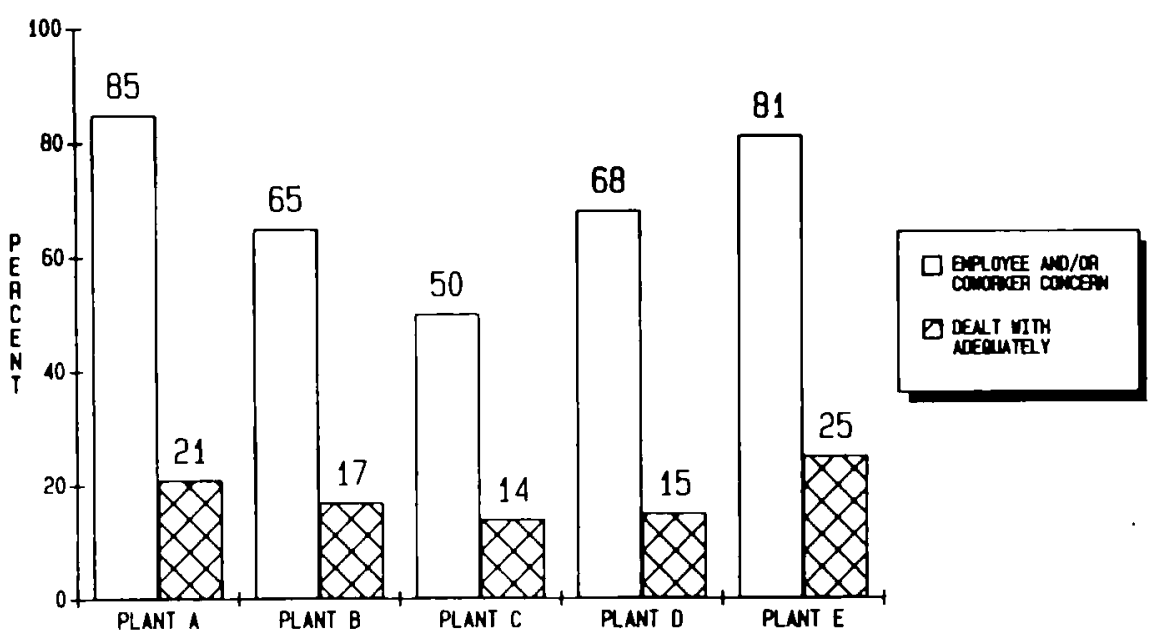

Figure 6. Mean Percent of Prior Concerns (and Percent Reporting Such Concerns Were Dealt with Adequately) Reported by Employees About Health and Safety Issues.

\section{Organizational Impacts}

\section{Handling of Health and Safety Prior to Training Program}

As shown in Figure 6, while a majority of employees in the five plants had health and safety concerns prior to the training program, only a small minority (14-25\%) of those with concerns felt they had been dealt with adequately before the program. Several employees attributed this to a lack of knowledge and information, as indicated by the following quotes:

There was a lag time in getting safety equipment and providing information. Also, people weren't aware enough to ask questions.

Millwright

I was never instructed on the hazards of solvents. I used my bare hands to clean parts; I ignored the fumes; I used improper gloves.

Pipefitter

There were inconsistencies from management in saying what was safe and what wasn't safe. I sensed they lacked the knowledge.

Equipment attendant

\section{Hourly Eniployee Actions}

Hourly employees were asked whether they had taken any steps in the last six months to get health and safety hazards corrected. Among those interviewed one year after training was completed, $22 \%$ said they had taken some action to resolve a health and safety problem. Among those who had taken action, 62\% reported they had handled the situation differently because of the training. In the majority of cases, 


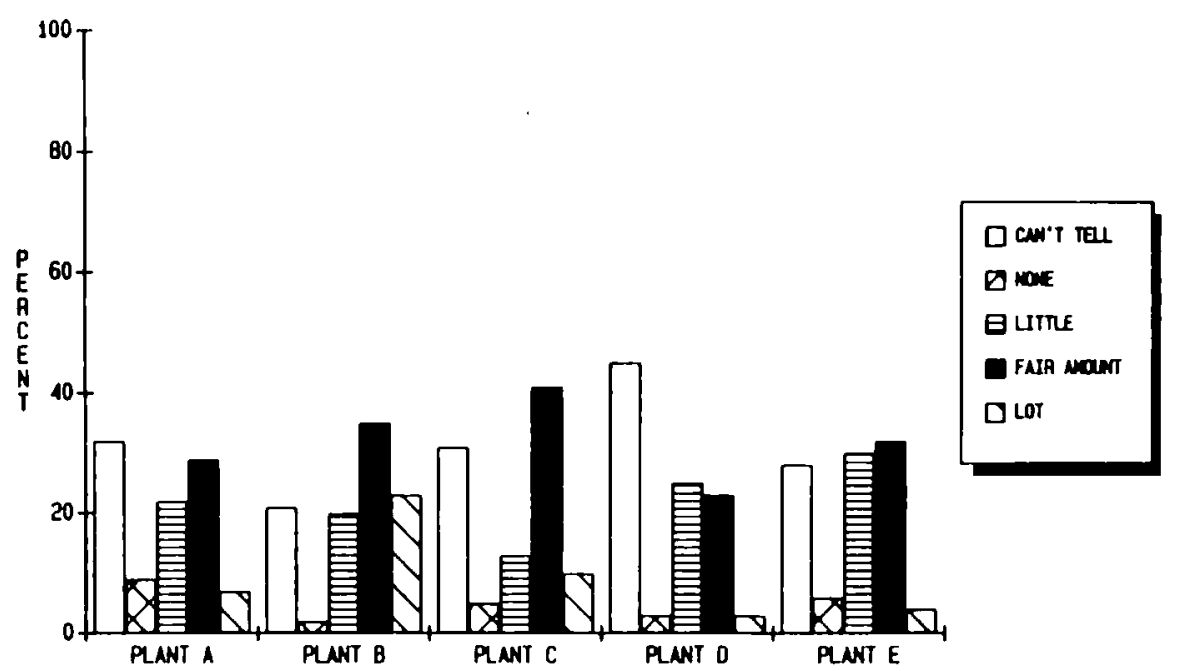

Figure 7. Effect of Program on How Health and Safety Issues Handled as Reported by Employees.

these actions consisted of talking to someone in the plant who was presumably in a position to get the problem corrected. Employees most frequently contacted supervisors, safety personnel, or union representatives. A few employees reported trying to correct the problem on their own.

Several trainers and supervisors noted that increased requests for action by hourly employees affected the handling of health and safety issues:

There is more awareness, employees ask more readily to fix things and they are fixed more quickly now.

An employee might complain of a problem. I meet with the safety engineer or area managers; we had much less say in this respect in the past.

\section{Handling of Health and Safety}

As shown in Figure 7, the majority of employees in the five plants felt that the program had a small to moderate effect on how health and safety issues are handled in their plants. However, almost one-third were unable to say whether the program had an impact.

Among those who felt the program had a significant impact, the most frequently reported types of effects included: increased awareness of potential health and safety hazards; more concern on the part of the union and company; greater availability of information on hazards; better housekeeping practices; and quicker responses when problems occurred.

There were also differences in reported program impact by plant. Employees at Plants $B$ and $C$ reported the greatest effect on handling of health and safety issues, with over $50 \%$ saying the effect was either "a fair amount" or "a lot." 


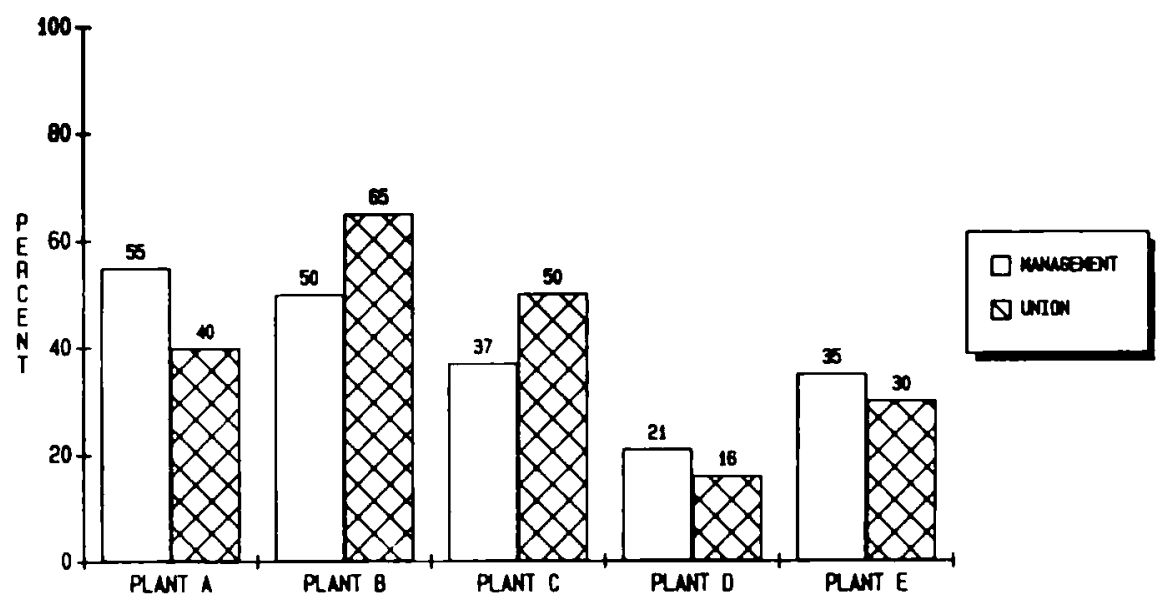

Figure 8. Percent of Employees Reporting Changes in Management and Union Attitude toward Health and Safety since the Program.

\section{Health and Safety Personnel}

Although employees were not asked directly about the impact of the training program on the role of health and safety personnel, several provided unsolicited comments. The majority of comments suggested that both union and company personnel had taken a more active role in dealing with health and safety issues, as evidenced by the following comments:

The safety engineer offers assistance and listens more.

Millwright

The safety engineer is stricter; more visible on the floor; checks jobs more.

Plumber/pipefitter

The (union) health and safety person is down there more now. I think it's a new person or new position.

Production worker

\section{Company and Union Concern}

Two years after program completion, $52.1 \%$ of employees across the five plants reported that the union was "very" concerned about health and safety versus $32.9 \%$ who reported the company was "very" concerned. Forty percent of the interviewed employees felt that there had been a change in management's attitudes toward health and safety. The percentages ranged from $21 \%$ at Plant D to $55 \%$ at Plant A. (See Fig. 8 ). Several employees mentioned that this change in management's attitude was illustrated by a greater willingness to give employees information and deal with problems. The following comments are typical: 
They send people around to check on things more, for example, that guards rails are up and that there's no oil on the floor.

Machine operator

They come to safety meetings now and hear from us directly.

Assembler

Forty percent of the employees also mentioned they had seen changes in the union's attitude toward health and safety. The percentages ranged from $16 \%$ at Plant D to $65 \%$ at Plant B. (See Fig. 8). Several employees mentioned that the union now takes a more active role in dealing with health and safety issues and is able to act more effectively:

They're morc willing to deal with problems. They tell employees to call the safety man if they think there's a problem.

Relief man

They're around more asking questions. If you need something done, they do it right away.

Repairman

Now the union can argue more effectively on our behalf because they know the problems and facts about hazards.

Plumber/pipefitter

\section{Supervisors}

Asked about how different groups such as local plant management, local union, hourly employees, and supervisors appreciated and supported trainers' efforts, trainer interviews at all sites indicated that supervisors were the least supportive and appreciative of the program. Most trainers explained this lack of support with the difficulty supervisors faced in letting people off the job to attend training sessions. The following comments reflect this concern:

Some supervisors are more interested in getting production out . . . some are very negative, did not attend all sessions, viewed it as an employee program.

It hurt them to get people off the job; they were not always receptive to getting people here on time. This is just not on their minds.

Some trainers suggested that supervisors did not understand the scope of the program and that they should have been involved in introductory sessions.

Supervisors themselves were the only group interviewed that was not unanimously supportive of the training program. The most important reason for their more critical perspectives seemed to be insufficient information, as the following comments suggest:

I still don't have enough information regarding hazards. I'd be more supportive if I knew more.

Not enough depth. The program is hard to support because not all hazards are identified. Identification would reinforce commitment to safety. 


\section{DISCUSSION}

Several key findings of the evaluation of the training program merit emphasis. First, the program was completed at all five plants with the intended basic framework, i.e., it was delivered by joint labor-management training teams to over $95 \%$ of employees using the intended materials.

Second, beyond this basic framework, there were striking differences in program delivery across the five plants. These variations in training development and delivery were reported to be related to the absence of specific corporate or divisional implementation guidelines. As a result, the particular approach to training and resource allocation selected at each plant appeared to be strongly influenced by the role played by the local union, local plant management's attitude toward the program and the outcome of negotiations at the local plant level.

Third, a strong association was seen between conditions of training delivery and many of the program impacts examined. The plants (B and C) with more favorable conditions for training delivery (delivery at the beginning of a shift, frequent breaks for oral presentations and questions, more suitable physical facilities, smaller groups, more time spent per unit, higher total trainer hours per week spent on program per 100 employees) evidenced more favorable trainer and employee assessment of the training's usefulness, greater reported changes in employee work practices, greater reported changes in working conditions, and greater reported changes in organizational handling of health and safety problems.

Fourth, the program appeared to be at least moderately successful in all five plants in meeting the specific written information and training requirements of the Federal Hazard Communication Standard. Most employees reported increased availability of information on chemical hazards (including signs, container labels, and material safety data sheets) and most found the program "somewhat" or "very" helpful in recognizing hazards and knowing how to handle hazardous situations.

In addition, as suggested in the preamble of the standard, "the increased availability of hazard information" appeared to "give employees the information they need to protect themselves." In the 1-year follow-up survey, $60 \%$ of the employees reported having changed their work practices because of the program. After two years, $42 \%$ still reported having changed their practices. In interpreting these figures one should keep in mind that some workers had participated in prior health and safety education programs. Furthermore not all jobs involved potential exposure to hazardous chemicals. In fact, at the 2-year survey, among workers who reported no hazards on their job, $10 \%$ reported changing their work practices as compared to $48 \%$ reporting changes among those who reported their jobs to be slightly, moderately, or extremely hazardous. Finally, although the training program attempted to be comprehensive, both hourly employees and trainers suggested that it had not covered all actual hazards. Thus, the failure to change work practices may have been an "appropriate" response in some instances.

Fifth, the program appeared to have beneficial effects on health and safety conditions and practices in the plants which went beyond the stipulations of the Standard. Both trainers and hourly employees suggested the program had resulted in improvement in health and safety control measures ranging from increased availability of personal protective equipment to substitution of safer chemicals for more hazardous ones. The program also was credited with positive effects on the organizational ap- 
proach to health and safety issues. Employee responses suggested a significant need for improvement in this area as only $20 \%$ of those hourly employees who had health and safety concerns prior to the program felt that such concerns were dealt with adequately then. By both trainer reports and employee self reports, hourly employees were more likely to take effective actions to have health and safety problems corrected after the training program. Those with direct health and safety responsibilities (company safety engineers and union health and safety representatives who, for the most part, were also trainers) were reported to be more willing and more able to deal effectively with health and safety problems. Finally, across the five plants $40 \%$ of hourly employees reported changes in both plant management's and the local union's attitudes toward health and safety.

Sixth, several weaknesses in planning and implementation were identified which appeared to decrease program effectiveness. As mentioned above, the lack of specific corporate guidelines on either methods of training delivery or resource allocation contributed to significantly less effective training delivery at some of the plants. The lack of sufficient orientation of and early input from key management and union personnel at the local plants also appeared to contribute to resistance to the suggested methods of program implementation. Similarly the failure to orient and enlist the support of front-line supervisors stands out as a particular weakness. These supervisors were noted to be the least supportive group in the plants yet some of the findings suggest their support to be critical for a successful program. For example, trainers emphasized the difficulty of conducting the program in the face of supervisor resistance to release of hourly employees to attend sessions. Again, hourly employee reports of change in their own work practices were strongly associated with reports of changes in the attitudes of their direct supervisor.

Another notable weakness involves the time pressures associated with program delivery. Full training materials including videos were not available until five months before the legal deadline for completion of training. Several trainers as well as plant management representatives described being overwhelmed with the magnitude of the task to be completed in this time frame. Finally, the choice of trainers mostly on the basis of job responsibilities rather than training ability and interest also appeared to decrease the effectiveness of training delivery in some plants. Discomfort with their roles as trainers or simple disinterest in the program on the part of some trainers so chosen appeared to have promoted an overreliance on videos as "stand alone" training tools in some plants. Some union members of the NJC suggested that the choice of union health and safety representatives as trainers without regard to ability was based on "political expediency."

Certain limitations of the evaluation process also deserve comment. First, while the evaluation is strengthened by a longitudinal design including three waves of data collection, it is weakened by the lack of a true baseline. The evaluators were unable to obtain data at the five local plants prior to initiation of training, rather the first wave was collected during the active training phase. Thus, some measures of change had to rely on recall of respondents. Second, owing to a combination of logistical difficulties and concern that the presence of outside observers would alter the behavior of plant personnel resulting in non-representative observations, no direct observation of work practices, work conditions, or methods of resolving health and safety issues was attempted. These measures are based instead on questioning of respondents. However, the consistency of responses obtained in the two waves of data collection and across 
plant personnel in a wide variety of job roles is reassuring regarding their reliability. Third, although the available records on use of PPE were consistent with responses on surveys, the overall availability of plant records relevant to the study is limited. Fourth, although both company and union members of the National Joint Committee suggested that the five plants investigated were a roughly representative sample of the program delivered across the corporation, we have no independent method to ascertain this. Despite some weaknesses in evaluation design, the authors believe the reported results to be a valid reflection of strengths and weaknesses of the training program.

\section{AN ECOLOGICAL MODEL FOR WORKPLACE DISEASE PREVENTION}

Our results suggest that interdependent phenomena, occurring at several organizational levels, affected the process of program implementation. It appears that program successes and failures can best be assessed when the organization is viewed as a connected, holistic system. A conceptual framework was developed to better understand the implications of our results.

This conceptual framework is represented by the model shown in Figure 9. This model presents factors which interact to determine the risk of the development of work-related illness. Thus, the model can serve as a guide for the development and implementation of health education programs intended to reduce the risk of illness. It can be described as ecological in the sense that it views health and disease as outcomes of a complex system of interactions between the individual worker and multiple levels of environmental influences. ${ }^{10,11}$ The model views health as a property of the overall work environment rather than just of the individual worker. ${ }^{11}$ It posits five levels of interacting factors which determine the intensity, frequency, and duration of exposure of individual workers to chemical and physical hazards and thus, together with individual susceptibility, determine the risk for the development of work-related disease.

An examination of the successes and failures of the training program in the context of this model leads us to several interrelated hypotheses that appear to have significant implications for the design of workplace health education programs. It appears that an intervention strategy will be most effective to the extent it is able to: (1) incorporate existing intraorganizational relations in a manner to promote adoption of the program; (2) influence multiple levels of the organization and, especially, target those groups which most affect how health and safety issues are handled; and (3) increase the competencies and predisposition of the overall organizational system to address health issues. Below, each of these hypotheses in relation to our evaluation results are examined.

The ecological model suggests that, in viewing the corporation and the local plant as communities of interacting individuals and groups, an intervention strategy will be most effective if it is designed to incorporate the existing intraorganizational relations in a manner to promote rather than hinder adoption of the program. The training program discussed in this article presents a mixed picture of successes and failures in this regard. At the corporate/international union level, driven by the legal requirements of the federal standard and building on a strong history of labor-management cooperation in health and safety, the NJC agreed upon an overall structure for the training program. However, the NJC did not set guidelines for methods of program delivery or allocate or specify allocation of resources for the program thus apparently contribut- 
LEVEL 1: SOCIETAL FACTORS

LEGAL ECONOMIC CULTURAL

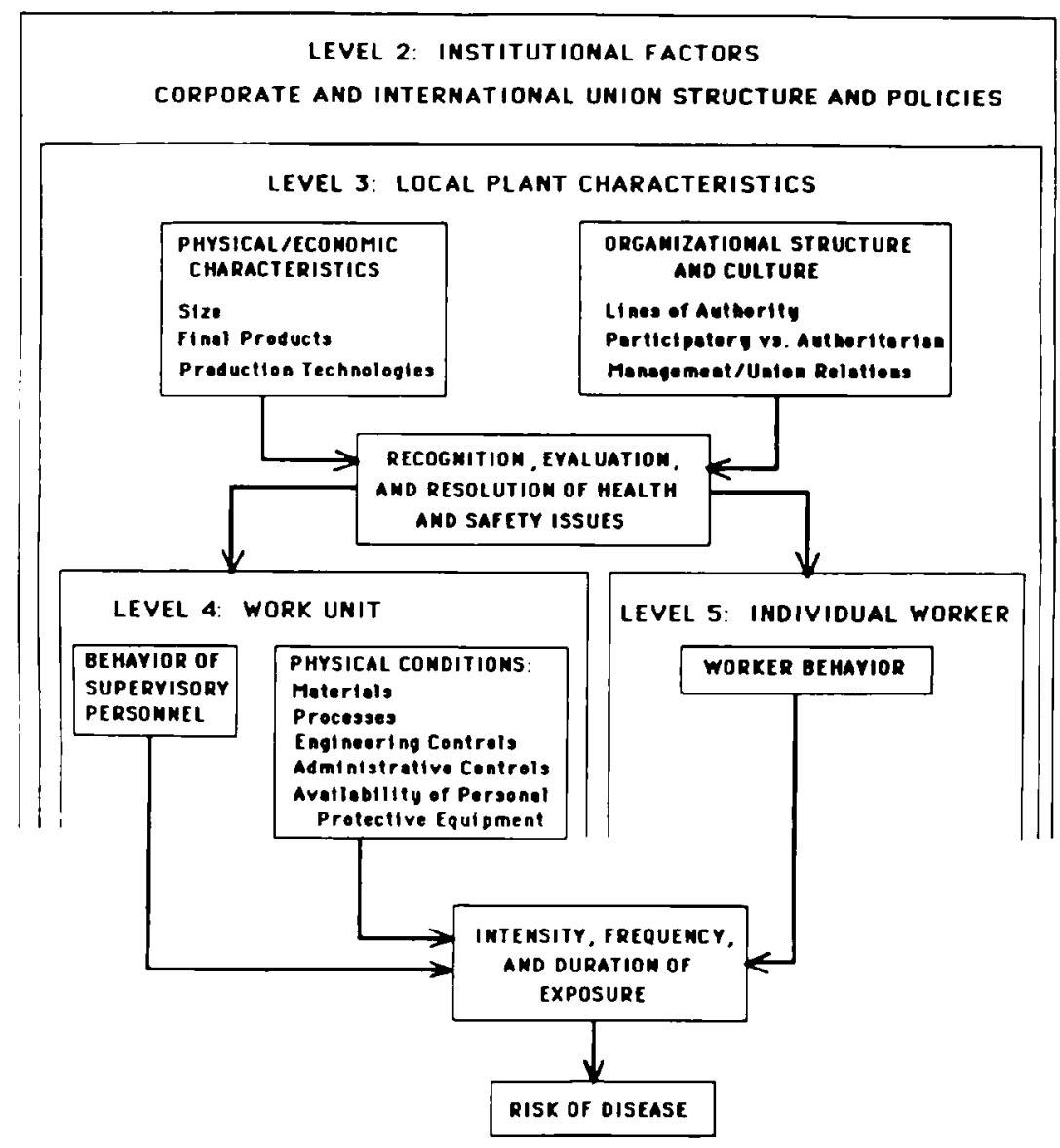

Figure 9. An Ecological Model of Worksite Disease Prevention.

ing to a high degree of variability in the quality of the program in different plants. Moreover, although management and union leadership at the local plants had final responsibility for program delivery, these groups were not included in planning the overall program structure. This may have contributed to resistance on the part of some local plant management to the delivery of a program of this magnitude. On the other hand, the program appeared to have enhanced credibility among hourly employees because it was planned and delivered jointly by labor and management.

The model also suggests that a successful training program needs to influence the knowledge, attitudes, and behavior of not only the individual hourly worker but also of direct supervisory personnel, plant personnel with explicit health and safety responsibilities, and plant management and union leadership as well. In particular, a successful program will target those groups which most affect how health and safety issues are handled. In the present case, the training materials emphasized not only safer individual work practices but also an understanding of engineering methods to control hazards and recognition of and reporting of hazardous conditions to proper personnel. 
In addition, the training program was delivered to front line supervisors and other plant personnel as well as to hourly employees. Those with explicit health and safety responsibilities (company safety engincers and union health and safety representatives) had the most intensive exposure to the program in their roles as trainers. Moreover, the train-the-trainer week included extensive discussion of the importance of responding effectively and systematically to employee health and safety concerns. The choice of in-plant personnel who already have health and safety related responsibilities as trainers has the potential advantages of (1) embedding knowledge ${ }^{15}$ on health and safety at the most critical points in the organization (i.e., in the individuals with the greatest responsibility), (2) helping to ensure that these key individuals "buy in" to the program, and (3) having direct training of employees performed by personnel who are both intimately familiar with local plant conditions and accountable to the employees for handling of health and safety problems. There is evidence that these strategies of addressing organizational issues in the training materials, delivering training to front-line supervisors as well as hourly employees, and involving those with explicit health and safety responsibilities as trainers had positive effects. Across the five plants, improvements in health and safety control measures were noted. Hourly employees appeared more likely to take effective action to have health and safety problems corrected following the program. Nearly two-thirds of supervisors reported changing their own work practices. Company safety engineers and union health and safety representatives were reported to be more willing and able to deal effectively with health and safety problems. On the other hand, the use of those with explicit health and safety responsibilities as trainers may have decreased program effectiveness in cases in which trainers lacked the ability, interest, or time to participate effectively. Furthermore, the results suggest that front-line supervisors are a key group both in ensuring a smoothly running program and in promoting safer work practices and working conditions. However, there appeared to be a failure to educate supervisors about the importance of the program or to ensure their cooperation in releasing employees to the training sessions.

Lastly, the ecological model of disease prevention implies that a successful program will demonstrate system learning, ${ }^{16}$ i.e., it should increase the competencies and predisposition of the overall system (i.e., organization) to recognize, evaluate, and ameliorate health and safety problems. There are several indications that a degree of system learning occurred in this setting. As discussed above, hourly employees and supervisors appeared more likely to request action on health and safety issues, and personnel with specific health and safety responsibilities were reported to be more able and willing to resolve these issues. In addition, respondents suggested that other personnel only indirectly concerned with health and safety, such as process engineers responsible for choosing production materials, now gave greater consideration of health effects in their decisions. Many respondents noted an enhanced willingness and ability of the union and company to work together on health and safety. Perhaps the strongest evidence of system learning we obtained is from the planning of a new joint training program on certain types of safety hazards which was initiated after preliminary evaluation results of the hazard communication training program (HCTP) became available. National Joint Committee members explained that, on the basis of experience with and evaluation of the HCTP, design of the new safety program would differ in the following respects: (1) strict guidelines with regard to total number of hours of training per employee, hours of training per employee delivered per day, group size, and 
mixing of videos with workbook exercises, discussions, and question and answer sessions; (2) selection of trainers on the basis of communication skills with company safety engineers and union health and safety representatives playing only a back-up role; (3) orientation sessions for local plant management and union personnel; and (4) development of performance oriented training materials through focus groups including the target trainee population. Finally, in assessing the extent to which system learning has occurred, one should keep in mind the perceptions of hourly employees. Although 40\% reported a change in both management's and the union's approach to health and safety, another third felt unable to say whether any change had occurred suggesting the impact of the program at this level may have been somewhat limited.

\section{IMPLICATIONS FOR WORKPLACE HEALTH EDUCATION}

It is believed that the results reported here have several important implications for the most effective design of workplace health education programs. First, these results suggest that health educators who adhere, explicitly or implicitly, to an ecological model of disease prevention similar to the one presented in this article will enjoy more success in designing interventions. Specifically, it is believed that (1) a successful intervention strategy must assess and incorporate existing intraorganizational relations in a manner to promote adoption of the program; and (2) the intervention needs to influence the knowledge, attitude, and behavior of individuals working at various organizational levels so as to positively affect how the organization addresses health issues as a system. Second, these results provide strong evidence that the incorporation of adult education principles into decisions regarding who should deliver training, program content, mix of delivery methods, and time and group size limits on training sessions will greatly improve program outcomes. Finally, these results suggest that the promotion, to the extent feasible, of joint labor-management involvement in the planning and delivery of education programs is likely to enhance program credibility and impact. While these lessons are drawn from experiences with an education program on work-related illness, it is believed that they are applicable to most workplace based health education or health promotion programs.

\section{References}

1. Levy BS. Wegman DH: Occupational Health. Boston. Little Brown, 1983.

2. US Department of Labor, Bureau of Labor Statistics: Illnesses and injuries by industry, 1978.

3. Page JA, O'Brien WA: Bitter Wages. New York, Grossman Publishers, 1973.

4. Berman DM: Death on the Job. New York, Monthly Review Press, 1978.

5. Patty, FA, (ed): Industrial Hygiene and Toxicology. New York, Interscience Publishers. Inc., 1948, Vol. 1:34

6. Sloan RP: Workplace health promotion: A commentary on the evolution of a paradigm. Health Education Quarterly 14:181-194, 1987.

7. Castillo-Salgado: Assessing recent developments and opportunities in the promotion of health in the American workplace. Social Science and Medicine 19(4): 349-358, 1984.

8. Federal Register, August 24, 1987. 
9. Federal Register, Vol. 48, No. 228:53280, November 25, 1983.

10. Hugentobler, MK, Schurman, SJ: Hazard communication training program: trainthe-trainer phase: evaluation report: Institute of Labor and Industrial Relations, University of Michigan, October 1985.

11. Robins TG, Klitzman S, Alcser K: Evaluation of the hazard communication training program: progress report. Department of Environmental and Industrial Health, University of Michigan, December 12, 1986.

12. Robins TG, Byosiere P, Hugentobler MK, Kaminski M, Klitzman S: Evaluation of the hazard communication training program: interim report. Department of Environmental and Industrial Health, University of Michigan, January 22, 1988.

13. Levi L: Preventing Work Stress. Reading, Mass., Addison-Wesley Publishing Company, 1981 .

14. McLeroy KR, Bibeau DL: An ecological model for worksite health promotion. Paper presented to the American Public Health Association Annual Meeting, Las Vegas, Nevada, September 30, 1986.

15. Rogers EM, Shoemaker FF: Communication of Innovations. New York, The Free Press, 1971.

16. Susman GI, Evered RD: An assessment of the scientific merits of action research. Administrative Science Quarterly 23:582-603, 1984. 